\title{
HONDURAS 2019: PERSISTENTE INESTABILIDAD ECONÓMICA Y SOCIAL Y DEBILIDAD INSTITUCIONAL
}

\author{
Honduras 2019: Persistent Economic and Social Instability and \\ Institutional Weakness
}

\section{CECILIA GRACIELA RODRÍGUEZ}

Universidad de Salamanca, España

\section{LUIS GONZÁLEZ TULE}

Universidad del Norte, Colombia

\begin{abstract}
RESUMEN
Este trabajo analiza el escenario en que se encontró Honduras durante el año 2019, a través de la revisión de indicadores económicos y de los acontecimientos sociales y políticos más relevantes acaecidos en el país centroamericano. El 2019 se distinguió por la persistencia o empeoramiento de problemas de larga data. En materia económica, los escasos avances resultan insuficientes para reducir los altos niveles de pobreza y desigualdad. En materia social, la violencia continúa como uno de los compromisos pendientes de la segunda administración de Juan Orlando Hernández. Mientras que en materia política la corrupción vuelve al centro del debate y no cesan los abusos de poder y las violaciones a los derechos humanos. Todos estos factores han aumentado el descontento social expresado en manifestaciones multitudinarias y provocado la emigración de miles de hondureños.
\end{abstract}

Palabras clave: Honduras, política económica, violencia, migración, corrupción.

\begin{abstract}
This work analyzes the scenario in which Honduras found itself during 2019, through the review of economic indicators and the most relevant social and political events that have occurred in the Central American country. 2019 was distinguished by the persistence or worsening of long-standing problems. In economic terms, limited progress is insufficient to reduce the high levels of poverty and inequality. In social matters, violence continues as one of the pending commitments of the second administration of Juan Orlando Hernández. While in political matters, corruption returns to the center of the debate and abuses of power and human rights violations do not stop. All these factors have increased the social discontent expressed in social movements and have caused the emigration of thousands of Hondurans.
\end{abstract}

Keywords: Honduras, Economic policy, Violence, Migration, Corruption. 


\section{INTRODUCCIÓN}

Luego de un año convulso, el 2019 se anticipaba como un potencial punto de inflexión para la segunda administración del presidente Juan Orlando Hernández -y tercera consecutiva del Partido Nacional de Honduras (PNH), que desde la crisis política de 2009 se afianzó en el poder-. No hay que olvidar que desde que Hernández logró postularse como candidato para competir por un segundo periodo y ganar las elecciones a finales de 2017, a través de una controvertida interpretación de la Corte Suprema de Justicia, pues hasta antes de eso la Constitución prohibía la reelección (Rodríguez y González 2020), dio inicio otra crisis política marcada por la falta de legitimidad hacia el mandatario, por lo que miles de personas decidieron tomar las calles para manifestarse mientras el gobierno, en respuesta, reprendió haciendo uso de la fuerza pública. La reelección de Hernández abrió nuevos frentes de conflicto entre el gobierno, por un lado, y la oposición y sociedad civil, por otro. Esto no sólo ha traído como corolario que el mandatario reaccione con mayor arbitrariedad frente a la inconformidad, sino que persistan o se agudicen algunos problemas de larga data.

En el plano económico el escenario en 2019 se presentaba estable, aunque sin triunfalismos porque los pocos avances en la materia no han mejorado la calidad de vida del grueso de la población. El crecimiento económico continuó por encima de la media regional, pero cayó con relación a años anteriores; los niveles de pobreza y pobreza extrema se redujeron tímidamente, aunque no en todo el país de manera homogénea; y la desigualdad se mantuvo igual que en años previos, para ubicarse como una de las más altas de América Latina.

En el terreno social la violencia proveniente de las pandillas no cesó a pesar de la reducción en el número de asesinatos; mientras que la migración continuó en sus múltiples modalidades, incluso con el endurecimiento de medidas por parte de EE.UU. En temas políticos la inestabilidad institucional ha estado presente desde el inicio del segundo mandato de Hernández: se abandonó el combate a la corrupción, aun cuando Honduras aparece como uno de los países más corruptos del continente, ${ }^{1} \mathrm{y}$ se abrieron nuevos conflictos para el gobierno, sobre todo en el frente interno. Entre ellos, destaca la detención de Juan Antonio "Tony" Hernández, exdiputado nacional y hermano del presidente, quien fue acusado de narcotráfico en EE.UU., lo que reactivó la ola de inconformidad.

Bajo ese contexto nos proponemos analizar los eventos más relevantes en Honduras durante 2019 en los escenarios arriba mencionados. Para ello el artículo está organizado en tres apartados. Como punto de partida, el primero de estos se dedica a repasar el desempeño de la economía hondureña. El segundo apartado aborda la coyuntura social, poniendo especial atención a dos problemas pendientes de gran preocupación internacional: violencia y migración. El tercero se aboca al análisis del panorama político, los estrechos vínculos con el nar-

Según el informe publicado por Transparencia Internacional, Venezuela, Nicaragua y Honduras son los países con el mayor nivel de corrupción en el año 2019, con una puntuación de 16, 22 y 26 puntos respecti- 
cotráfico y el malestar social que se ha visto duramente reprimido. El artículo finaliza con unas breves conclusiones.

\section{ESCENARIO ECONÓMICO}

En materia económica 2019 fue un año de escasos resultados para Honduras. A pesar de un incremento en su economía por encima de la media regional, gran parte de la población sufre las malas condiciones en que se encuentra el país centroamericano (carencia de servicios públicos, pobreza, falta de empleo y marginación). El bajo desempeño está asociado, entre otros motivos de índole político-social, con un crecimiento económico desigual concentrado en ciertos sectores, como el sistema financiero o de telecomunicaciones que no generan empleos de productividad (Forbes 2020), y con la vulnerabilidad de la estructura productiva, ya que las principales exportaciones hondureñas son productos primarios y manufactura de bajo valor agregado (Marques et al. 2019).

De manera que 2019 cerró con un 2.7\% de crecimiento, registrando una disminución de $1.1 \%$ con respecto a 2018, año en que se ubicó como el segundo país con mayor crecimiento sostenido en Centroamérica, sólo después de Panamá. Dejando atrás también el promedio anual de 4\% entre 2015 y 2018 (Gráfico 1). En esos años la economía se desarrolló sobre la base de: 1) un proceso de modernización de la administración tributaria, lo que garantizó al Estado mayor recaudación de impuestos (Marques et al. 2019), 2) altos ingresos por remesas y 3) un contexto externo favorable para las exportaciones. Pero en 2019 algunas áreas estratégicas como la agricultura, pesca y ganadería mostraron menor dinamismo. En concreto, cayeron los precios internacionales del café, el principal producto de exportación, y tuvieron un mal desempeño los cultivos de banano, la producción de azúcar y la crianza de camarón y peces (FOSDEH 2019).

Gráfico 1. Crecimiento económico en Honduras 2015-2019 (\%)

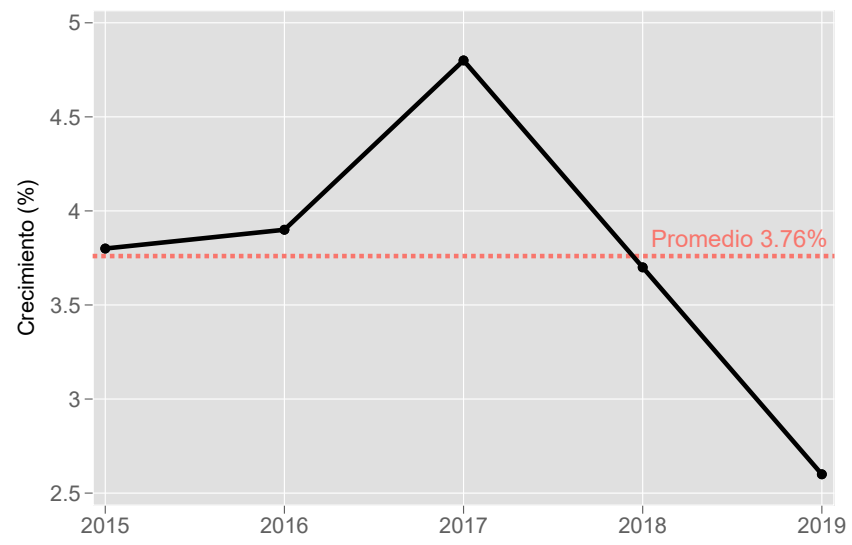

Fuente: Banco Mundial para 2015-2018 (2020) y Banco Central de Honduras para 2019 (2020a). 
La política monetaria continuó siendo restrictiva para controlar la inflación. El año cerró con una inflación de $4.08 \%$, muy cercana al $4.22 \%$ del año previo, para converger dentro del punto medio del rango de tolerancia establecido por el Banco Central de Honduras (BCH). Los productos y servicios que más contribuyeron al incremento de la inflación fueron algunos alimentos de origen agropecuario -huevo, frijol, hortalizas y tubérculos-, bebidas no alcohólicas, transporte y salud. El índice de precios al consumidor mostró incrementos prácticamente en todas las regiones a nivel nacional (BCH 2020b).

En relación con la pobreza, según cifras oficiales obtenidas a través de la Encuesta Permanente de Hogares de Propósitos Múltiples (EPHPM 2020), en 2019 el 59.3\% de los hogares en Honduras se encontró en condición de pobreza, ya que sus ingresos se situaron por debajo del costo de una canasta básica de consumo. Esta cifra representa una disminución del 2.6\% frente a 2018, registrándose los mejores resultados en zonas urbanas en donde la reducción en tres años fue de 8.2 puntos porcentuales, para ubicarse en $52.5 \%$ en 2019 . El problema se agudiza en las zonas rurales, en donde la pobreza alcanza al 68.2\% de los hogares. Como puede apreciarse en el Gráfico 2, de 2016 a 2017 la pobreza rural se dispara 6 puntos llegando a su punto más alto luego de la crisis política y social de 2017, acelerada por la reelección de Juan Orlando Hernández.

Gráfico 2. Evolución de la pobreza en Honduras 2015-2019 (\%)

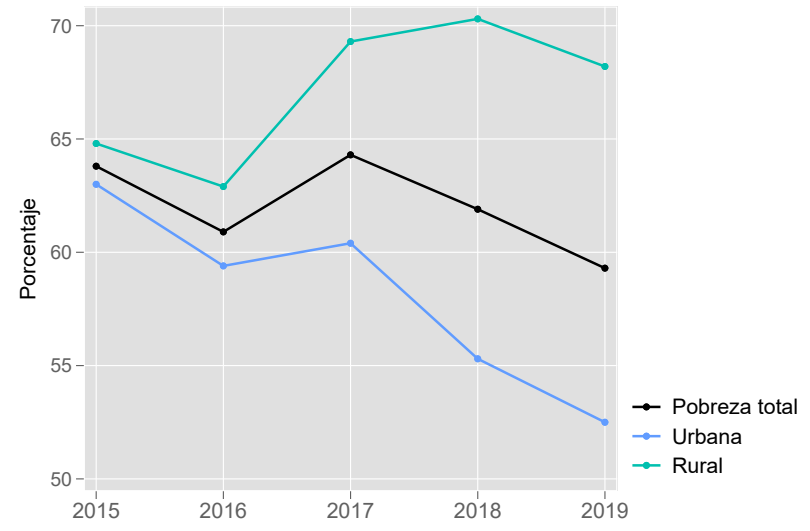

Fuente: EPHPM (2020).

Si del gráfico anterior se desprende que alrededor de dos de cada tres hogares hondureños ha vivido en condición de pobreza, el siguiente gráfico (3) destaca que uno de cada tres sobrevive con menos de 1.90 dólares al día, ${ }^{2}$ esto es, en pobreza extrema. Al desagregar los datos se observa la desigualdad que divide 
los centros urbanos de las periferias. Del 36.7\% de los hogares en condición de pobreza extrema durante 2019, el $57.2 \%$ habitaba en zonas rurales, en contraste con el $21 \%$ de las áreas urbanas. Los niveles más bajos de pobreza y pobreza extrema se encuentran en el Distrito Central (43.8\% y 13.6\%, respectivamente) y en San Pedro Sula ( $43.8 \%$ y 14.7\%, respectivamente). En el resto de los centros urbanos el $56.7 \%$ de los hogares se encuentra en pobreza y el $24.5 \%$ en pobreza extrema (EPHPM 2020).

Gráfico 3. Evolución de la pobreza extrema en Honduras 2015-2019 (\%)

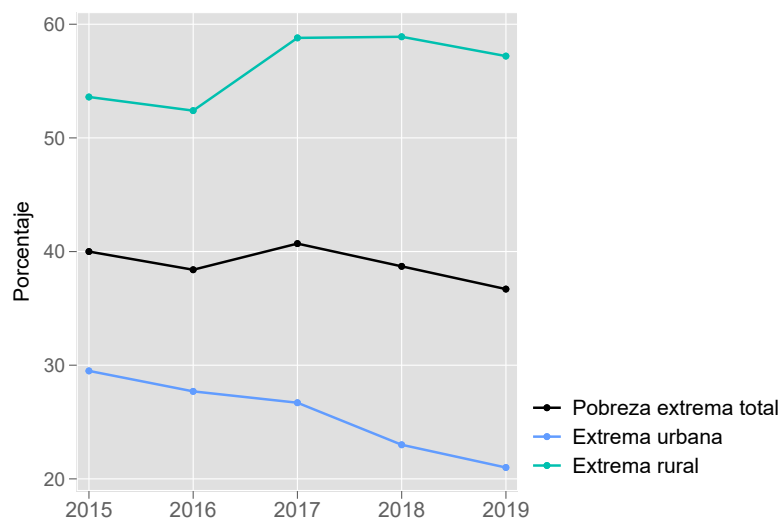

Fuente: EPHPM (2020).

Es notorio que el desarrollo económico se ha concentrado en determinados centros poblacionales y en ciertos sectores productivos, mientras que el mayor rezago se encuentra en la población que habita las zonas rurales del país, en donde no sólo aumenta la incidencia sino también la brecha social. De ello da muestra la estructura de los trabajos. En áreas urbanas, en 2019 el número de personas ocupadas de la población económicamente activa alcanzó el $54.7 \%$, mientras que en las rurales el $45.3 \%$. Las ciudades concentraron $73 \%$ de los trabajos en el sector público y $63.4 \%$ del privado, frente a las zonas rurales que ocuparon el $27 \%$ del mercado laboral en el sector público y $36.6 \%$ del privado (EPHPM 2020). Esto sugiere que las ciudades concentran mayor cantidad de trabajadores, aunque no necesariamente se traduzca en mayores oportunidades, pues el desempleo en la ciudad fue mayor $(7.8 \%)$ al de las zonas rurales $(3.0 \%)$.

Continuando con el mercado laboral, la división genérica del trabajo es manifiesta. Del 57.3\% de la población económicamente activa en 2019, el 63\% de los ocupados eran hombres y sólo el $37 \%$ mujeres. El desempleo también fue mayor en el sector femenino el cual alcanzó una tasa de 8.1\%, lo que representaba casi el doble del masculino (4.2\%). Otra brecha es el salario, en promedio nacional las mujeres percibían un $6 \%$ menos que los hombres a pesar de tener mayor grado de escolaridad (EPHPM 2020). Esto denota que la desigualdad 
obedece a la falta de oportunidades y espacios de desarrollo más que a la falta de capacidades.

Por otro lado, la desigualdad en la distribución de la riqueza continúa como uno de los grandes pendientes del PNH durante los tres mandatos que ha permanecido al frente de la Presidencia de la República. Un análisis de la evolución de la desigualdad, medida a través del Índice de Gini, revela que ésta se mantiene constante a lo largo de la última década con valores muy altos. El promedio para el periodo 2009-2018 fue de 0.53, cerrando el año 2019 con un coeficiente de 0.52 (Tabla 1). Esto ubica a Honduras como uno de los países más desiguales en Latinoamérica.

Tabla 1. Desigualdad en Honduras 2009-2019 (coeficiente de Gini)

\begin{tabular}{cccccccccccc}
\hline Año & 2009 & 2010 & 2011 & 2012 & 2013 & 2014 & 2015 & 2016 & 2017 & 2018 & 2019 \\
\hline Gini & 0.53 & 0.54 & 0.55 & 0.57 & 0.54 & 0.52 & 0.51 & 0.52 & 0.52 & 0.53 & 0.52 \\
\hline
\end{tabular}

Fuente: EPHPM (2020).

El Gráfico 4 ilustra mejor lo anterior. Los ingresos per cápita del quintil más alto han aumentado más de un diez por ciento en los últimos cinco años, al pasar de 7965 Lempiras mensuales en 2015 a 9917 en 2019, un equivalente a US\$400 (al tipo de cambio que estableció el BCH en diciembre de 2019). Mientras que los ingresos del quintil más bajo sufrieron una pérdida de $5 \%$ en cinco años. Esto sin considerar la inflación, por lo que el impacto real sobre el poder adquisitivo es mayor. El ingreso promedio mensual entre 2015 y 2019 para este sector fue de 450 Lempiras, aproximadamente US\$18 (EPHPM 2020).

Gráfico 4. Evolución de la desigualdad en el ingreso de los hogares más ricos y los más pobres (en Lempiras)

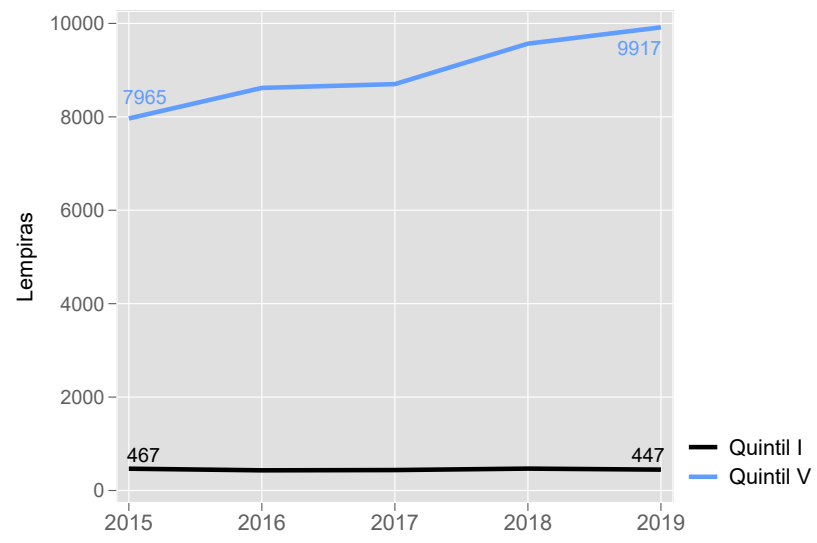

Fuente: EPHPM (2020). 
En lo que concierne a la deuda externa pública, el año 2019 no presentó variaciones con respecto a años previos. Esto como resultado de una política fiscal más eficiente en la recaudación de ingresos y controles de gasto. Así, la deuda pública externa en 2019 ascendió a US\$7690 millones, 4.4\% superior a 2018 (Gráfico 5). En términos porcentuales la deuda equivale al 30.8\% del Producto Interno Bruto (PIB) de Honduras, apenas $0.1 \%$ más que el año anterior. Este porcentaje permanece por debajo del límite prudencial recomendado por el Banco Mundial que establece una cifra inferior a 36\%.

El nuevo endeudamiento externo contratado para 2019 fue de US\$733.1 millones. Según el Gobierno Central, los recursos serían destinados para apoyo presupuestario (US\$419.5 millones) y para proyectos y programas (US\$313.6 millones). Si bien este último monto se encuentra dentro de la política de endeudamiento público para el periodo 2019-2024, la cual establece un total de US $\$ 450.0$ millones para la ejecución de proyectos y programas, cabe destacar que el préstamo solicitado en un año representa el 70\% de lo estipulado para un periodo de cuatro años.

Gráfico 5. Deuda externa pública de Honduras 2016-2019*

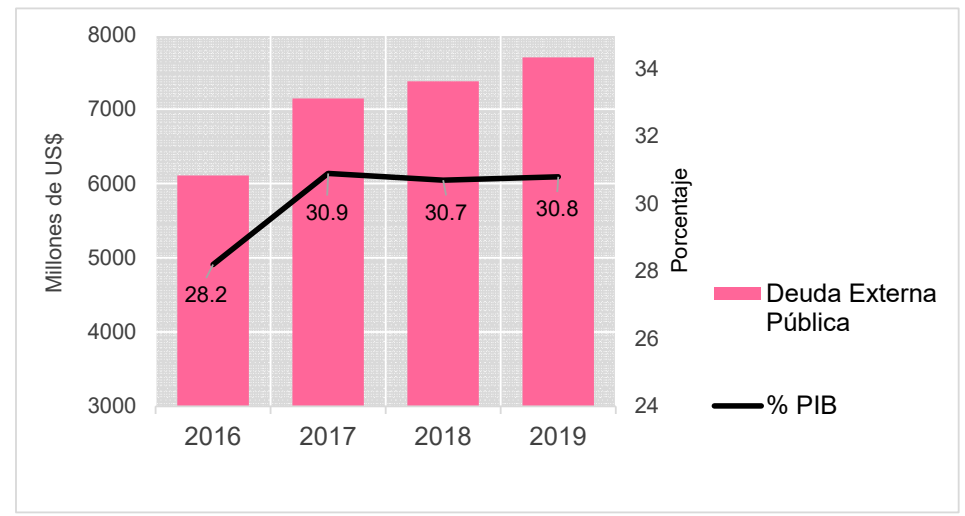

* En millones de dólares y su equivalencia en porcentaje del PIB Fuente: Banco Central de Honduras (2020c).

Para concluir esta sección es importante considerar que, a pesar del desempeño macroeconómico -crecimiento por encima de la media regional, ligera disminución de la pobreza total y extrema, control de la inflación y manejo de la deuda externa-, los resultados deben tomarse con cautela por las dificultades y debilidades de la propia economía hondureña. Dentro de éstas destaca la concentración de bienes primarios de poco valor agregado en sus exportaciones, los cuales son fácilmente afectados por variaciones en los precios internacionales (Marques et al. 2019). 
Asimismo, que el país se encuentra en una zona susceptible a los efectos del cambio climático, cuyo impacto ya se ha sentido en la reducción de playas, aumento de temperaturas, sequías y erosión de suelos (El Heraldo 2019). Por último, el impacto de la desaceleración del crecimiento de remesas, debido, principalmente, a las medidas migratorias en EE.UU. A las debilidades económicas ya expuestas, se suman los problemas político-sociales que azotan al país. De hecho, como se verá más adelante, los resultados económicos favorables no han impactado positivamente en la imagen del presidente, quien ha visto perder sostenidamente su aprobación sobre el rumbo del país desde su reelección en 2018 (Gráfico 10).

\section{ESCENARIO SOCIAL}

El año 2019 avizoraba la persistencia de dos problemáticas sociales que han acompañado a la democracia hondureña durante décadas, pero en los últimos años con distintos matices. Una de ellas es la elevada tasa de violencia y criminalidad, que ubica a Honduras como uno de los países más peligrosos del mundo. La violencia que ahora azota al país, a diferencia de la década de 1980, proviene principalmente de las pandillas que se dedican a diversas actividades delictivas. La otra problemática es la migración de miles de hondureños, quienes se ven obligados a abandonar el país huyendo de la inseguridad y la falta de oportunidades, más allá de buscar el sueño americano.

Los delitos violentos son un problema generalizado en Honduras. El país sigue presentando una de las tasas de homicidios más altas del mundo, a pesar de la reducción de estos delitos en los últimos años. El año 2019 registró un repunte en la tasa de muertes por homicidios, al pasar de 41.4 homicidios cada 100,000 habitantes en el 2018 a 42.8 en el 2019 (Gráfico 6). Esta cifra ubica a Honduras como el país más inseguro de Centroamérica ${ }^{3}$ y entre los más peligrosos de la región, sólo le superan Venezuela y Jamaica, con una tasa de 60.3 y 47.4 respectivamente (Asmann y O’Reilly 2020).

La presencia continua de los elevados niveles de violencia en el país ha motivado un endurecimiento de las políticas de seguridad en las últimas administraciones del Partido Nacional. Tanto la gestión de Porfirio Lobo (2010-2014) como los años de administración de Juan Orlando Hernández (2014-2018 y 2018-actualmente) han implementado políticas de "mano dura", centradas en el control de la seguridad por parte de los militares. ${ }^{4}$ Estas políticas de "mano

Tanto El Salvador como Guatemala registraron un marcado descenso en los niveles de violencia, con una tasa de homicidios de 36 y 21.5 respectivamente (Asmann y O’Reilly 2020).

4 Entre las medidas adoptadas se encuentran la creación de la Policía Militar del Orden Público (PMOP), una unidad militar de más de dos mil miembros a la que se le encomendó la seguridad y el combate al crimen organizado. Además, se puso en marcha, en septiembre de 2014, la Tropa de Inteligencia y Grupos de Respuesta Especial de Seguridad, conocidos como los TIGRES, una unidad de élite subordinada a la Secretaría de Defensa y adscrita a la policía nacional preventiva, cuya labor principal es la lucha contra el crimen organizado. 
Gráfico 6. Muertes por homicidios. Comparativo 2004-2019 (tasas x 100,000 hab.).

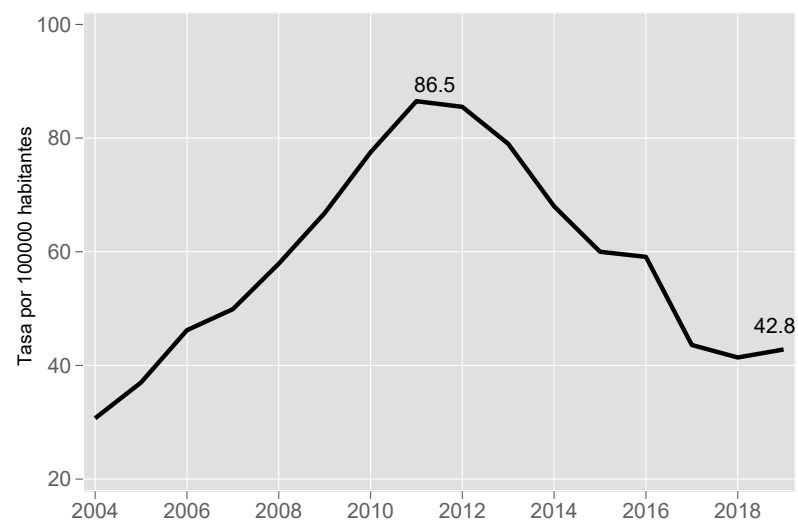

Fuente: Observatorio de la Violencia, Universidad Nacional Autónoma de Honduras (2020).

dura" están dirigidas principalmente a mitigar el amplio poder ejercido por las pandillas, como Barrio 18 y la MS13, ${ }^{5}$ que concentran principalmente sus actividades criminales en las zonas urbanas más pobladas del país, incluyendo la capital Tegucigalpa, el polo económico de San Pedro Sula y la ciudad costera de La Ceiba, sobre el Caribe.

Si bien los arrestos de líderes pandilleros fueron una muestra del éxito de las fuerzas de seguridad, las consecuencias imprevistas de estas acciones acarrearon dos grandes inconvenientes: en primer lugar, fomentaron el crecimiento de las pandillas mediante la concentración de muchos miembros en la cárcel, lo cual les permitió reorganizarse y reagruparse. En segundo lugar, provocaron una expansión de las "clicas", como se les denomina a las células de las pandillas, en algunas zonas del país que tradicionalmente no manifestaban ese problema. ${ }^{6}$

Durante años, la Comisión Interamericana de los Derechos Humanos (CIDH) ha dado seguimiento a los altos niveles de inseguridad ciudadana en Honduras y sus efectos en el goce efectivo de los derechos humanos. En este sentido, destacan que las políticas implementadas por el Estado hondureño para depurar y reformar a la Policía Nacional, han contribuido en la reducción de homicidios en el país. No obstante, esta reducción en los niveles de violencia no incluye a sectores muy vulnerables de la población, que se ven cada vez más afectados. Los sectores a los que hace referencia son: periodistas, ambientalis-

La Pandilla Callejera 18, también conocida como "Barrio 18", al igual que su rival más conocida, la Mara Salvatrucha (MS13), son las pandillas más violentas de la región y con fuerte presencia desde Centroamérica hasta Estados Unidos. Cuentan con miles de miembros a lo largo de cientos de kilómetros, e intereses en diversas actividades ilícitas.

6 Tras el arresto de líderes pandilleros, han proliferado el crimen y la violencia en municipios que "tradicionalmente han sido pacíficos" en los departamentos de Santa Bárbara, El Paraíso, Choluteca, Atlántida y Comayagua (La Tribuna 2019). 
tas, defensores de los derechos humanos, mujeres y miembros de la comunidad LGTB (lesbianas, gais, personas transgénero y bisexuales).

El 2019 registró el asesinato de 3 periodistas -Edgar Joel Aguilar, Santiago Carvajal y Leonardo Gabriel Hernández- (La Vanguardia 2019). Estos sucesos ponen en evidencia la dificultad de trabajar en favor de la libertad de prensa y de ejercer el periodismo de investigación en el país, siendo ésta una de las profesiones que sufre amenazas y actos de violencia de manera continua. ${ }^{7} \mathrm{La}$ violencia contra periodistas y la impunidad de esos crímenes afecta seriamente el ejercicio del derecho a la libertad de expresión en Honduras.

Asimismo, la CIDH considera que Honduras es uno de los países más peligrosos de América Latina para los defensores de derechos humanos, al registrar numerosos asesinatos de activistas. Entre ellos, generaron gran repercusión el asesinato de Salomón Matute y su hijo Juan Samael Matute en febrero de ese año, ambos miembros de la comunidad indígena Tolupan que pertenecían a la tribu de San Francisco Locomapa y miembros de la ONG "Movimiento Amplio por la Dignidad y la Justicia" (MADJ) (La Prensa 2019a). El asesinato de Salomón Matute se produjo a pesar de ser beneficiario de medidas cautelares otorgadas por la CIDH el 19 de diciembre de 2013, tras analizar la situación de riesgo que enfrentaba junto a otros integrantes del MADJ producto de amenazas, hostigamientos y actos de violencia en el marco de su labor como defensores del medio ambiente y pueblos indígenas.

De igual manera, generó repudio el asesinato de María Digna Montero, miembro de la Organización Fraternal Negra Hondureña (OFRANEH) y defensora de la tierra y la cultura de la comunidad indígena Garífuna. El asesinato de esta activista en octubre de 2019, se suma a una larga lista de homicidios, cometidos a lo largo de los últimos años, a defensores del territorio y la cultura garífuna. ${ }^{8}$ El año 2019 también representó un aumento de los reportes de asesinatos de personas hondureñas LGBT (Gráfico 7). La violencia basada en la identidad de género o la orientación sexual es un problema extendido en Honduras, siendo la comunidad LGTB uno de los sectores más vulnerables. Los datos proporcionados por el Observatorio de Muertes Violentas de LGTB de Honduras, posicionan a Honduras como el país con el mayor número de crímenes de odio hacia la comunidad LGTB en Centroamérica, quedando la mayoría de ellos en la impunidad (Rosales y Salazar 2019).

El Comisionado Nacional de los Derechos Humanos de Honduras, CONADEH, denunció el asesinato de 79 periodistas entre octubre de 2001 y septiembre de 2019. El 91 \% de esos casos seguía impune.

La presidenta de la Organización Fraternal Negra de Honduras (OFRANEH), Miriam Miranda, denunció un plan que consiste en asesinatos selectivos de líderes garífunas. Este asesinato, junto al de otros 16 líderes garífunas, en el año 2019- permanece impune (Telesurtv 2019). 
Gráfico 7. Número de muertes violentas de miembros de la comunidad LGTB por año

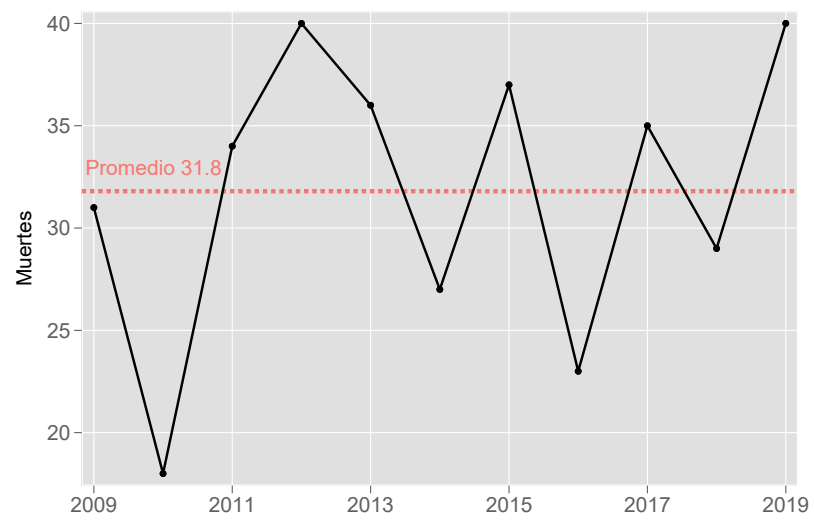

Fuente: Observatorio de Muertes Violentas de LGTBI de Honduras.

La segunda problemática social que enfrentó Honduras durante 2019 deriva en gran medida de las cuestiones previamente abordadas. Y es que la migración no cesa a pesar de que las dificultades son cada vez mayores. Ante los peligros e inconvenientes del viaje por tierra -extorsiones, secuestros, trata, abusos sexuales, asaltos, detenciones y deportaciones-, el 12 octubre de 2018 inició una nueva modalidad migratoria con la primera caravana que partió de San Pedro Sula. El viaje en caravana garantizaba mayor protección a los emigrantes. Al grupo de cerca de 2.000 hondureños que abandonó el país se fueron adhiriendo personas de distintas partes del continente americano, pero en su mayoría salvadoreños y guatemaltecos. Se estima que al llegar a México el número ascendía a más de 4.000 individuos. A lo largo de todo el mes continuaron los llamados para reunirse y migrar a través de esta modalidad hasta que el 31 de octubre partió la cuarta caravana desde San Salvador con cerca de 800 personas (Observatorio de Legislación y Política Migratoria 2018).

Pero esta nueva modalidad ha tenido que sortear nuevos obstáculos. Tras el arribo de la primera caravana a territorio mexicano, el presidente Enrique Peña Nieto ordenó detenerla en la frontera con Guatemala. Ante las acciones emprendidas por Peña Nieto, el presidente electo, Andrés Manuel López Obrador (AMLO), prometió que cuando tomara posesión -en diciembre de 2018- otorgaría visas de trabajo a los inmigrantes (Rodríguez 2019). La llegada de AMLO y su discurso en contra de la opresión y a favor del respeto a los derechos humanos, auguraba un futuro alentador para el grupo de centroamericanos que intentaba cruzar el territorio con dirección a los EE.UU. En efecto, en enero de 2019 se permitió el ingreso y libre circulación a la primera caravana del año, pero la buena voluntad del mandatario duró sólo tres meses. La política migratoria de AMLO cambió luego de que el presidente estadounidense Donald Trump impusiera aranceles a las importaciones de algunos productos mexi- 
canos. En abril de ese año una nueva caravana procedente de Honduras fue detenida en la frontera con Guatemala (Martínez 2019).

Las medidas de Trump fueron más allá de los aranceles punitivos y del retiro de apoyo económico a los países que integran el Triángulo Norte de Centroamérica (TNC). El gobierno estadounidense presionó primero a México y luego a Guatemala, El Salvador y Honduras para que firmaran Acuerdos de Cooperación de Asilo (ACA). Estos acuerdos estipulan que EE.UU. puede deportar a México, Guatemala, El Salvador u Honduras a quienes hayan solicitado asilo atravesando alguno de estos países en su camino hacia el primero. De modo que un hondureño que se haya desplazado por tierra desde Tegucigalpa puede ser deportado a Guatemala o México mientras espera que su situación de asilo sea resuelta. Esto puede durar días, meses o años (Hines 2019).

El compromiso firmado por Trump y Hernández el 25 de septiembre de 2019, denominado Acuerdo entre el Gobierno de Estados Unidos de América y el Gobierno de la República de Honduras para la Cooperación en el Examen de las Reclamaciones de Protección, establece compromisos que atentan contra la vida de los inmigrantes, exceden la capacidad logística-operativa de los Estados receptores y, ante todo, favorece los intereses políticos del gobierno de Trump. Entre los puntos más controvertidos del acuerdo se encuentran los siguientes: 1) ambos países deben proporcionar protección a los refugiados elegibles que están físicamente presentes en su territorio; 2) Honduras no podrá devolver ni deportar a los inmigrantes que envíe EE.UU. y que se encuentren en proceso de asilo; 3) Honduras deberá garantizar acceso a la petición de asilo a los emigrantes que crucen por su territorio y otorgarles un proceso completo y justo; 4) los ciudadanos hondureños que pidan asilo a EE.UU. no serán devueltos a Honduras; 5) Honduras no podrá transferir ningún inmigrante enviado por EE.UU. hasta que este país tome una determinación final y; 6) Honduras no podrá disputar ninguna decisión tomada por EE.UU (Cansino 2019).

En opinión de expertos (Hines 2019: 68), lo que EE. UU buscó a través de estos mecanismos es "obstaculizar la llegada" de inmigrantes y el "acceso al sistema de asilo" de ese país. De otra forma sería difícil entender cómo El Salvador o Guatemala podrían servir como países seguros para los solicitantes, cuando el primero es uno de los países con mayor número de homicidios en la región y el segundo se ubica como uno de los más pobres (Hines 2019). Por ello la imposibilidad de los Estados latinoamericanos para cumplir con el contenido de los acuerdos no tardó en quedar en evidencia. ${ }^{9}$ El caso de México, que se convirtió

A pesar de que en la forma los ACA son una especie de acuerdo de Tercer País Seguro (TPS), el gobierno estadounidense evitó emplear esa denominación. Y no es extraño, pues un "tercer país seguro", según el Alto Comisionado de Naciones Unidas para los Refugiados (ACNUR), es un Estado diferente al de residencia habitual y destino que brinda protección a quien por su situación así lo requiera, "ya sea en relación con un caso individual específico o de conformidad con un acuerdo bilateral o multilateral entre los estados sobre el traslado de solicitantes de asilo" (ACNUR, 2018). Para ello, el tercer país debe garantizar seguridad "legal y física, incluyendo acceso a derechos civiles, políticos, económicos, sociales y culturales similares a los que disfrutan los nacionales" (ACNUR, 2018). Tales garantías están lejos de ser aseguradas por alguno 
en el principal receptor de solicitantes de asilo, refleja claramente la situación. A finales de 2019 habían sido devueltos a México por esta modalidad 62,144 inmigrantes, la mayoría del TNC $(44,703)$, de los cuales 22,930 eran hondureños (Tourliere 2020). Muchas de las personas que aguardan en la ciudad fronteriza mexicana de Matamoros, en el estado de Tamaulipas, se han visto obligadas a vivir en campamentos improvisados y son objeto de extorsiones perpetradas por oficiales locales y el crimen organizado (Hines 2019).

Pese al endurecimiento de las políticas migratorias y el riesgo que representa el viaje rumbo a EE.UU., es poco probable que la migración hondureña disminuya. Las cifras de detenciones en EE.UU. y México -y las condiciones estructurales y de inseguridad en Honduras- así lo sugieren. 2019 se convirtió en el año con mayor número de detenciones de hondureños tanto en EE.UU. como en México. El primero detuvo en sus fronteras a 254,561 personas, mientras el segundo a 66,377 en distintas partes del territorio (Gráfico 8). Las detenciones en 2019 constituyeron un aumento del 330\% en EE.UU. y del 11.2\% en México con respecto a 2018 .

Gráfico 8. Detenciones de hondureños en EE.UU. y México

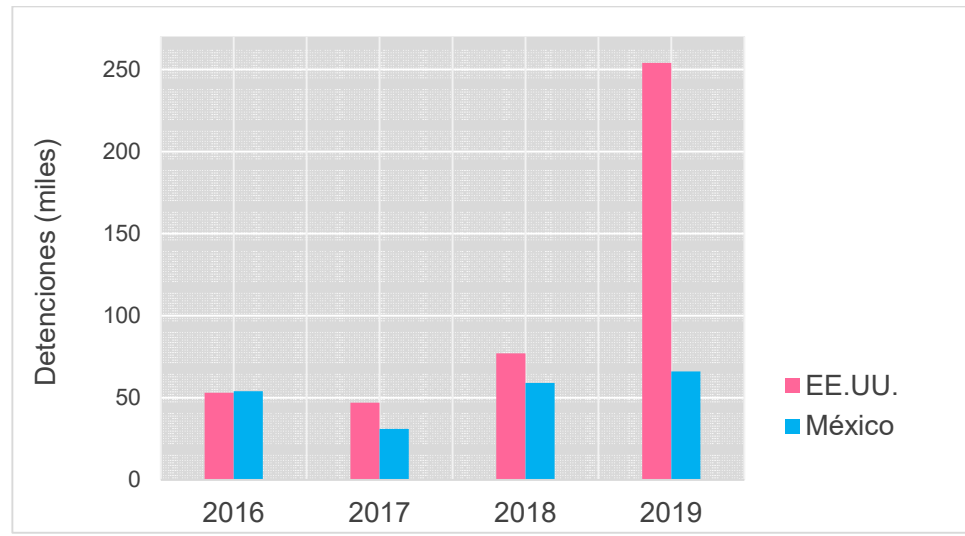

Fuente: Para Estados Unidos: U.S Border Patrol; para México: Unidad de Política Migratoria, Secretaría de Gobernación.

Un último factor para tener en cuenta en relación con la migración es la contribución de las remesas en el sostenimiento de miles de familias y su aporte a la economía nacional, ya que el dinero que envían los hondureños radicados en el exterior va en aumento y, a su vez, cada año constituye un mayor porcentaje del PIB (Gráfico 9). En 2019 la cifra ascendió a US\$5,650.2 millones, lo que repre-

de los países que integran el TNC y México. Por tal motivo las inconformidades no se hicieron esperar. En Guatemala, una semana después de anunciado el acuerdo, fueron interpuestos tres amparos ante la Corte de Constitucionalidad con el argumento de que el país no está en condiciones de afrontar el gasto ni de ofrecer protección a las personas que deba acoger (Global Affairs and Strategic Studies 2019). 
sentó un alza de 13.1\% en comparación a lo reportado en 2018. Este incremento no es exclusivo de 2019 sino que se ha sostenido por encima de $10 \%$ en los últimos cuatro años. De tal manera que las remesas son la principal fuente de divisas del país por encima de la maquila o la exportación del café; este recurso además ha servido para reducir el déficit de la balanza de cuenta corriente y aportar a la estabilidad de la Lempira (BCH 2020d).

Gráfico 9. Remesas familiares hacia Honduras (millones de dólares)

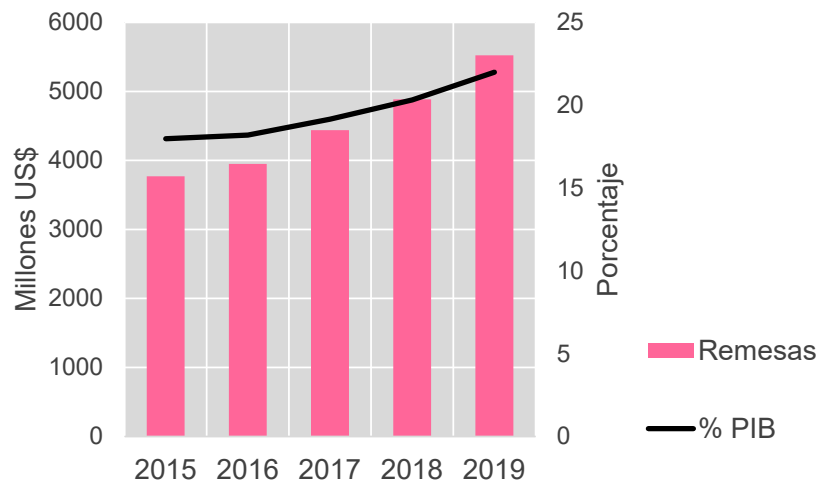

Fuente: Banco Central de Honduras (2020d).

\section{ESCENARIO POLÍTICO}

En el ámbito político, 2019 fue un año de inestabilidad en Honduras. La segunda administración de Hernández contó desde el inicio -27 de enero de 2018- con desconfianza social, secuela de la crisis poselectoral de $2017 .{ }^{10}$ La controvertida decisión de la Corte Suprema de Justicia, en 2015, al declarar inconstitucionales los artículos que prohibían la reelección presidencial, puso en duda la credibilidad de las instituciones del Estado, generando una ola de protestas que continuaron tras la celebración de las elecciones de 2017.

Hernández inició su segundo mandato con debilidad en el legislativo muy fragmentado. No obstante, ha logrado fortalecer sus alianzas y asegurarse una mayoría necesaria para sacar adelante su agenda legislativa. El partido del presidente $(\mathrm{PNH})$ cuenta con 61 representantes de los 128 que componen la Cámara Legislativa. A su vez, cuenta con el apoyo de siete diputados de otras

10 En las elecciones generales de 2017 resultó reelecto el Presidente Juan Orlando Hernández, lo cual generó rechazo y cuestionamientos en algunos sectores de la ciudadanía, debido a que la Constitución Política de Honduras no permitía la reelección presidencial. Asimismo, durante el proceso electoral, amplios sectores de la sociedad cuestionaron la falta de transparencia del sistema de transmisión electrónica, y el recuento de votos, ente otras falencias. Los resultados, y sobre todo la "caída del sistema" de publicación de resultados por aproximadamente diez horas fueron altamente cuestionados (Rodríguez 2019; Rodríguez y González 2020). 
agrupaciones políticas y la oposición la componen 60 legisladores provenientes del Partido Libre, el Partido Liberal y el Partido Innovación y Unidad Social Demócrata (PINU). Esta mayoría ha permitido reforzar la injerencia del Ejecutivo en el Legislativo, debilitando la institucionalidad del sistema.

Con respecto al Poder Judicial, el fallo de la Corte Suprema a favor de la reelección del Presidente planteó dudas sobre su independencia. Las fuerzas opositoras informaron de abuso de poder y manipulación del Poder Judicial. Esta denuncia confirmó la ya delicada situación de la magistratura. Pese a que la Constitución garantiza la separación de poderes, existen injerencias por parte del Poder Ejecutivo que obstaculizan la imparcialidad del proceso judicial.

En el escenario político, la complejidad del entorno doméstico acentuada en el 2019 , aunado a conflictos externos robustecieron la crisis política e institucional del país. En el plano doméstico, numerosas protestas sociales fueron cuestionando -cada vez más- las medidas adoptadas por Hernández en su gestión. A su vez, un incidente a nivel internacional dejó al descubierto estrechos lazos entre las estructuras del narcotráfico con miembros de la élite política nacional.

La crisis político-social estalló en abril, tras la promulgación de dos decretos orientados a reorganizar el área de educación y salud. Desde entonces, una avalancha de protestas fue arrinconando cada vez más al presidente. Los movilizados, bajo la consigna "Fuera JOH"-las iniciales del presidente-, solicitaron la derogación definitiva de estas medidas, al considerar que suponían despidos masivos de personal y la privatización de la salud y la educación (DW 2019). Aunque las regulaciones fueron derogadas en abril, las protestas continuaron.

En este conflicto dos actores de gran relevancia se posicionaron de manera distinta, por un lado, la Conferencia Episcopal emitió un comunicado en el que manifestó su preocupación con la gestión de Hernández ${ }^{11}$, y los actos de represión cometidos durante las protestas realizadas. Por el otro lado, los militares dejaron en evidencia su total apoyo al presidente, quienes se desplegaron para contrarrestar las protestas (Salinas 2019). Durante este período las fuerzas de seguridad utilizaron armas de fuego, gases lacrimógenos y balas de goma, provocando muertes y heridos entre los manifestantes.

Por su parte, organizaciones de derechos humanos denunciaron que, en la represión que tuvo lugar entre abril y julio, al menos seis personas perdieron la vida, 80 resultaron heridas y se produjeron 48 detenciones arbitrarias. Asimismo, la Oficina del Alto Comisionado para los Derechos Humanos en Honduras (OACNUDH) y la Comisión Interamericana de Derechos Humanos (CIDH), expresaron su preocupación por los señalamientos de que las fuerzas de seguridad habían disparado con armas de fuego a los manifestantes e indicaron

11 La Conferencia Episcopal se sumó recientemente a esta crítica: "Si cada problema deriva en conflictos como el que ahora estamos viviendo, acerca de los sistemas de salud y de educación, y si cada conflicto es manejado con la misma ineficiencia, las consecuencias pueden hundir a Honduras en una crisis muy difícil de superar", advirtieron los obispos en un comunicado inusualmente contundente (Weiss 2019) 
que, a partir del golpe de Estado de 2009, las violaciones a los derechos humanos son una constante en el país. Tal como informa Amnistía Internacional, las políticas represivas del gobierno de Hernández para responder a protestas han sido condenadas anteriormente. ${ }^{12}$

Otro caso documentado por Amnistía Internacional sobre uso excesivo de la fuerza, y que provocó un fuerte rechazo, fue la incursión a la Universidad Nacional Autónoma de Honduras (UNAH) el día 24 de junio, cuando miembros de la Policía Militar entraron al recinto y dispararon contra decenas de personas que se estaban manifestando. En un comunicado de prensa, el gobierno justificó este actuar por la necesidad de rescatar a un oficial privado ilegalmente de la libertad por parte de algunos estudiantes, así como por el empleo de bombas molotov y otros artefactos lanzados en contra de las fuerzas del orden, y la necesidad de "persuadir" y "repeler el ataque", algo que fue desmentido por los manifestantes (Amnistía Internacional 2020).

Tal como puede apreciarse en el gráfico 10, los datos correspondientes al año 2019 ponen en evidencia la fuerte crisis socio-política que atraviesa el país (La Prensa 2019b). Así, en el marco de un rechazo creciente hacia su gestión y su imagen, un incidente internacional minó aún más la popularidad de Hernández, al conocerse el Fallo de la Fiscalía Federal de Estados Unidos que condenó a "Tony" Hernández -hermano del presidente y ex congresista por el PNH- como narcotraficante. ${ }^{13}$ La Fiscalía Federal de Estados Unidos aseguró que Tony Hernández operaba con total impunidad y que pertenecía a una organización auspiciada por el Estado que distribuyó cocaína durante años. Asimismo, el documento judicial de Estados Unidos denunció que la campaña presidencial de Hernández de 2013 fue financiada en parte por narcotraficantes. Dicha declaración provocó la indignación ciudadana, que no dudó en salir a manifestarse reclamando la renuncia de Juan Orlando Hernández.

12 El 13 de junio de 2018, Amnistía Internacional publicó el informe Prohibido Protestar: Uso de la Fuerza y Detenciones Arbitrarias como Estrategia para Reprimir la Disidencia en Honduras, en el que se documenta cómo las autoridades emplearon una fuerza excesiva para reprimir a personas que protestaban de manera pacífica inmediatamente después de las polémicas elecciones del 26 de noviembre de 2017.

13 "Tony" Hernández, fue detenido en noviembre de 2018 en Miami y enviado a Nueva York para ser procesado por hechos ocurridos entre 2004 y 2016. Durante su juicio, que se inició el 2 de octubre de 2019, surgieron importantes detalles sobre sus actividades ilícitas y sus vínculos con grupos de narcotráfico de Colombia, Honduras y México, incluyendo a Joaquín “El Chapo” Guzmán Loera (BBC 2019). 
Gráfico 10. Valoración de la gestión del presidente Juan Orlando Hernández

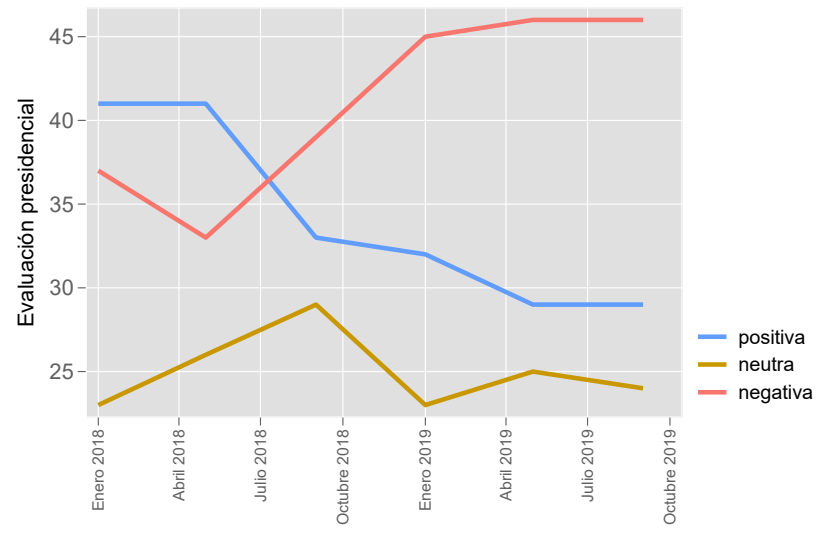

Fuente: CID-GALLUP/La Prensa (2019b)

Un último punto para tener en cuenta en este apartado, son los elevados niveles de corrupción que demuestran, una vez más, la fragilidad institucional de Honduras. El último informe de Transparencia Internacional que presenta los resultados del Índice de Percepción de Corrupción (IPC ${ }^{14}$ ) del año 2019, otorga a Honduras una puntuación de 26 puntos sobre un total de 100, ubicándose muy por debajo de la media regional (43) ${ }^{15}$. En el año 2019, Honduras bajó significativamente su calificación con una reducción de 5 puntos desde 2015 (Tabla 2). Esto ubica a Honduras como uno de los países más corruptos de la región.

Tabla 2. Índice de Percepción de Corrupción de Honduras 2015-2019

\begin{tabular}{cccccc}
\hline AÑO & 2015 & 2016 & 2017 & 2018 & 2019 \\
\hline IPC & 31 & 30 & 29 & 29 & 26 \\
\hline
\end{tabular}

Fuente: Transparencia Internacional.

Con respecto a la lucha contra la corrupción, a finales de año, se tomó una decisión que representó un paso hacia atrás, y fue cancelar, a partir de enero de 2020, la Misión de Apoyo Contra la Corrupción y la Impunidad en Honduras (MACCIH). Esta medida, emanada desde la Presidencia de la República de Honduras, llegó tras continuos bloqueos legales y extra-legales a las acciones

14 La clasificación realizada por Transparencia Internacional, abarca un total de 180 países y está elaborada por expertos y actores del sector privado. La puntuación del IPC correspondiente a un país o territorio indica el grado de corrupción en el sector público según la percepción de empresarios y analistas de país, en una escala de 0 (percepción de muy corrupto) a 100 (percepción de ausencia de corrupción).

15 Uruguay es el país latinoamericano mejor posicionado con 71 puntos y Venezuela, con 16 puntos, posee la puntuación más baja (Transparencia Internacional 2020) 
de la MACCIH por la élite gobernante ${ }^{16}$ generando indignación nacional e internacional. La MACCIH fue creada en el año 2016 como respuesta a la fuerte presión social, tras el escándalo que representó el desfalco del Instituto Hondureño de Seguridad Social (IHSS) en 2015. Este suceso provocó el inicio de un vigoroso movimiento de indignación ciudadana que reclamó la instalación de una comisión internacional contra la corrupción. El escándalo suscitó una reacción a nivel internacional de tal envergadura que el gobierno se vio forzado a acordar con la OEA la formación de la MACCIH-OEA (2016) ${ }_{1}^{17}$ con el objeto de combatir la corrupción y la impunidad en el país (Rodríguez y González 2020)

Si bien la duración de esta Misión fue muy breve, durante su gestión impulsó investigaciones de corrupción en los que estaban implicados altos funcionarios. Así, logró instalar una nueva institucionalidad en el país, conocida como circuito anticorrupción, sustentada en la creación de la Unidad Fiscal Especial Contra la Impunidad de la Corrupción (UFECIC) y en la constitución de los tribunales especiales en materia de corrupción. Con este diseño, el binomio MACCIH-UFECIC logró judicializar 12 casos de corrupción, que involucraron a más de cien personas, entre funcionarios públicos y particulares. ${ }^{18}$

Sin duda, las numerosas protestas sociales acaecidas a lo largo del año, el Fallo Judicial que condena al hermano del presidente como narcotraficante, con la consecuente confirmación de la existencia de vínculos del narcotráfico con la política, y la cancelación de la MACCIH en Honduras, dibujan un escenario político convulso. Tras cumplirse 10 años del golpe de Estado que supuso la salida de "Mel" Zelaya del poder, Honduras presenta, nuevamente, niveles de inestabilidad muy preocupantes.

\section{CONSIDERACIONES FINALES}

El transcurrir del año 2019 en Honduras se reveló más problemático para el gobierno de lo que se anticipaba. Se observó la persistencia de una serie de problemas que acompañan al país desde hace décadas. En materia económi$\mathrm{ca}$, mejoraron ligeramente algunos indicadores: crecimiento por encima de la media regional, ligera disminución de la pobreza total y extrema, control de la

16 El Congreso nunca atendió su propuesta de reformar la Ley de Secretos Oficiales — que impedía el acceso a la información pública en áreas clave relacionadas con la corrupción-, tampoco aprobó la Ley de Colaboración Eficaz, enviada al Congreso desde septiembre de 2017. Y en los últimos meses, todos los diputados del Partido Nacional, el partido en el poder, y sus aliados del Partido Liberal cerraron filas mediante la aprobación de varios instrumentos jurídicos que restablecen la inmunidad parlamentaria que fue abolida en 2003.

17 La Misión de Apoyo contra la Corrupción y la Impunidad en Honduras (MACCIH) fue creada el 19 de enero de 2016 por medio de un acuerdo firmado en Washington D. C. entre la OEA y el gobierno de Honduras presidido por Juan Orlando Hernández; convirtiéndose en la primera Misión de la OEA para el combate a la corrupción y la impunidad en un Estado miembro. Surgió con el objeto de mejorar la calidad de los servicios prestados por el sistema de Justicia de Honduras en la prevención y lucha contra la corrupción y la impunidad en el país.

18 Por primera vez una ex primera dama, esposa del expresidente Porfirio Lobo Sosa, no solo fue procesada judicialmente, sino que también fue condenada a 58 años de prisión por los delitos de apropiación indebida y fraude (Reischke 2019) 
inflación y manejo de la deuda externa. Sin embargo, hubo signos de fragilidad y dependencia por la falta de desarrollo interno y la poca diversificación de la economía, la cual depende en gran medida de exportaciones agropecuarias de bajo valor agregado y de las remesas. Esto ha contribuido al mantenimiento de niveles altos de pobreza y de desigualdad en el ingreso.

Otros de los problemas manifiestos en 2019 son el acelerado deterioro de las instituciones, corrupción, violencia e impunidad que socavan la estabilidad general del país. Todos estos factores han sido determinantes para que miles de hondureños huyan en busca de seguridad a pesar de las dificultades por las nuevas políticas antiinmigrantes de EE.UU. La permanente situación de inseguridad y criminalidad también viene afectando a periodistas, activistas políticos y sociales, y mujeres y miembros de la comunidad LGTB, cuyos agresores materiales e intelectuales rara vez son llevados ante la justicia.

Como quedó de manifiesto, el 2019 fue un año de gran movilización y conflictividad social, especialmente, entre abril y julio, teniendo como punto de partida las protestas antigubernamentales que se llevaron a cabo en todo el país, impulsadas por el anuncio del presidente Juan Orlando Hernández de reformas impopulares en materia de salud y educación en abril. Las protestas continuaron a pesar de la suspensión de las reformas, y se caracterizaron por un uso excesivo de la fuerza por parte de las autoridades encargadas de brindar seguridad.

De igual manera, la coyuntura política en estos meses estuvo marcada por los escándalos. Tal vez los más relevantes son aquellos que pusieron de manifiesto dos grandes debilidades de este país centroamericano. Por un lado, el Fallo Judicial en EE.UU. que condena al hermano del presidente como narcotraficante y saca a la luz pruebas que garantizan los vínculos estrechos del narcotráfico con la élite política. Este hecho nuevamente provocó manifestaciones multitudinarias solicitando la renuncia de un presidente muy cuestionado desde su candidatura y posterior reelección.

El segundo aspecto que marca el deterioro institucional es la cancelación de la MACCIH en el país. Los esfuerzos realizados por la institución durante cuatro años fueron escasos debido a los escollos interpuestos por la clase política. El desmantelamiento de la Misión, que tuvo como finalidad construir un nuevo sistema integral de transparencia y lucha contra la corrupción e impunidad y fortalecimiento del Estado de derecho, dejó un sentimiento de orfandad en la ciudadanía, que sigue luchando por superar un problema endémico que azota al país, y afectó la imagen internacional del mandatario, quien evidenció su rechazo a combatir la corrupción.

\section{REFERENCIAS}

Amnistía Internacional. 2020. “Honduras 2019." Recuperado el 21 de abril de 2020 de: https://www.amnesty.org/es/countries/americas/honduras/report-honduras/ 
Alto Comisionado de Naciones Unidas para los Refugiados (ACNUR). 2018. "Legal considerations regarding access to protection and a connection between the refugee and the third country in the context of return or transfer to safe third countries." ACNUR. Recuperado el 22 de abril de 2020 de: https:/ / www.refworld.org/docid/5acb33ad4. html

Asmann, Parker y Eimhin O'Reilly. 2020, 28 de enero. “Balance de InSight Crime de los homicidios en 2019." InSight Crime. Recuperado el 15 de marzo de 2020 de: https:/ / es.insightcrime.org/noticias/analisis/balance-homicidios-2019/

Banco Central de Honduras. 2020a. "Producto Interno Bruto e Ingreso Nacional Per-Cápita en Dólares, 2000-2019." Recuperado el 20 de marzo de 2020 de: https://www.bch. hn/pib_base2000.php

Banco Central de Honduras. 2020b. "Índice de Precios al Consumidor." Recuperado el 24 de marzo de 2020 de: https:/ /www.bch.hn/indice_precios_pub.php

Banco Central de Honduras. 2020c. "Informe de Deuda Externa Sector Público y Privado." Recuperado el 30 de marzo de 2020 de: https://www.bch.hn/honduras_deuda_externa.php

Banco Central de Honduras. 2020d. "Resultado Encuesta Semestral de Remesas Familiares." Recuperado el 27 de marzo de 2020 de: https://www.bch.hn/remesas_familiares. php

Banco Mundial. 2020. “Crecimiento del PIB anual de Honduras." Recuperado el 15 de marzo de 2020 de: https://datos.bancomundial.org/indicator/NY.GDP.MKTP.KD.ZG?locations $=\mathrm{HN}$

BBC. 2019, 19 de octubre. "4 revelaciones del juicio por narcotráfico contra Tony Hernández, hermano del presidente de Honduras (y qué dice sobre ese país)." BBC, 2019. Recuperado el 05 de noviembre de 2019 de: https:/ / www.bbc.com/mundo/noticias-america-latina-50103209

Cansino, Jorge. 2019, 29 de septiembre. "Los diez puntos clave del acuerdo migratorio que convierte a Honduras en un 'tercer país seguro.'" Univisión Noticias, Recuperado el 12 de marzo de 2020 de: https:/ / www.univision.com/noticias/inmigracion/los-10puntos-clave-del-acuerdo-migratorio-que-convierte-a-honduras-en-un-tercer-paisseguro

DW. 2019, 01 de junio. "Protestas en Honduras en contra del gobierno." en DW, Recuperado el 12 de junio de 2019 de: https:/ /www.dw.com/es/protestas-en-honduras-en-contra-del-gobierno/a-48997917

El Heraldo. 2019, 2 de octubre. "Honduras: Altas temperaturas y sequía se agudizarán por cambio climático." Recuperado el 7 de abril de 2020 de https:/ / www.elheraldo.hn/ pais /1323630-466/honduras-altas-temperaturas-y-sequ\%C3\%ADa-se-agudizar\%C3\%A1n-por-cambio-clim\%C3\%A1tico

Encuesta Permanente de Hogares de Propósitos Múltiples (EPHPM). 2020. Instituto Nacional de Estadística. Recuperado el 24 de marzo de 2020 de: https: / www.ine.gob.hn/V3/ ephpm/

Foro Social de la Deuda Externa y Desarrollo de Honduras (FOSDEH). 2019. Balance Realidad Nacional 2019. Tegucigalpa: FOSDEH/Agencia Suiza para el Desarrollo y la Cooperación.

Forbes. 2020, 3 de enero. "El 2020 un año poco alentador para la economía de Honduras." Recuperado el 25 de marzo de 2020 de: https: / forbescentroamerica.com/2020/01/03/ el-2020-un-ano-poco-alentador-para-la-economia-de-honduras /

Global Affairs Strategic Studies. 2019, 12 de diciembre. "Acuerdos de tercer país seguro: baja la migración centroamericana a EE.UU." Universidad de Navarra, Recuperado el 14 de abril de 2020 de: https://www.unav.edu/web/global-affairs/detalle/-/blogs/ acuerdos-de-tercer-pais-seguro-baja-la-migracion-centroamericana-a-eeuu

Hines, Barbara. 2019. "Las políticas migratorias de Donald Trump." Nueva Sociedad 284: 53-71.

La Prensa, 2019a, 29 de febrero. "Matan a tiros a dos indígenas tolupanes defensores del bosque en Locomapa, Yoro." Recuperado el 12 de marzo de 2020 de: https://www. 
laprensa.hn/sucesos /1262573-410/matan-a-tiros-dos-ind\%C3\%ADgenas-tolupanes-defensores-del-bosque-en-locomapa-yoro

La Prensa. 2019b, 24 de septiembre. "CID-GALLUP: Paz social es lo que más desean los hondureños." En La Prensa, Recuperado el 26 de septiembre de 2019 de: https:/ /www. laprensa.hn/honduras/1321650-410/encuesta-cid-gallup-paz-social-desean-hondurenos

La Tribuna. 2019, 17 de junio. “'Maras' y pandillas expanden células en 30 municipios." Recuperado el 20 de marzo de 2020 de: https://www.latribuna.hn/2019/06/17/maras-y-pandillas-expanden-celulas-en-30-municipios /

La Vanguardia, 2019, 31 de agosto. "Asesinado un periodista de televisión en Honduras, el tercero este año." Recuperado el 15 de marzo de 2020 de: https: / www.lavanguardia. com/vida/20190831/47107046723/asesinado-un-periodista-de-television-en-honduras-el-tercero-este-ano.html

Marques, Eduardo, Jordi Prat, Juan C. Vargas y María C. Acevedo. 2019. Honduras. Un enfoque territorial para el desarrollo, Nueva York: BID.

Martínez, Óscar. 2019, 2 de mayo. "AMLO engaño a una multitud de migrantes." New York Times. Recuperado el 18 de abril de 2020 de: https://www.nytimes.com/ es/2019/05/02/espanol/opinion/lopez-obrador-migrantes-mexico.html

Observatorio de Legislación y Política Migratoria. 2018, 19 de noviembre. Colegio de la Frontera Norte. Recuperado el 18 de abril de 2020 de: https: / / observatoriocolef.org/infograficos/cronologia-de-la-caravana-centroamericana/

Observatorio de la Violencia. 2020. Instituto Universitario en Democracia, Paz y Seguridad, Universidad Nacional Autónoma de Honduras. Recuperado el 12 de abril de 2020 de: iudpas.unah.edu.hn

Reischke, Martin. 2019, 19 de diciembre. "Honduras: incertidumbre en la lucha contra la corrupción." DW. Recuperado el 12 de febrero de 2020 de: https:/ /www.dw.com/es/ honduras-incertidumbre-en-la-lucha-contra-la-corrupci\%C3\%B3n/a-51739610

Rodríguez, Arturo. 2019, 17 de octubre. "AMLO anuncia plan de visas de trabajo a migrantes centroamericanos." Proceso. Recuperado el 18 de abril de 2020 de: https:/ /www. proceso.com.mx/555830/amlo-anuncia-plan-de-visas-de-trabajo-a-migrantes-centroamericanos

Rodríguez, Cecilia y Luis González. 2020. "Elecciones en Honduras 2017: debilidad institucional e incertidumbre electoral." En América Latina Vota (2017-2019), dirigido por Manuel Alcántara Sáez. Madrid: Tecnos, 325-356.

Rodríguez, Cecilia. 2019. "Elecciones bajo sospecha. Análisis de las elecciones generales en Honduras 2017." Estudios Políticos 54: 203-232.

Rosales, Paula y Pilar Salazar. 2019, 31 de diciembre. "2019: 67 asesinatos contra población LGBTI+ en Centroamérica." Agencia Presentes. Recuperado el 18 de abril de 2020 de: https://agenciapresentes.org/2019/12/31/67-asesinatos-en-2019-contra-poblacion-lgbti-en-centroaamerica-cifra-supera-2018/

Salinas, Carlos, 2019, 22 de junio. "Al menos tres muertos en Honduras tras el despliegue del Ejército por la oleada de protestas." Recuperado el 10 de abril de 2020 de: https:/ / elpais.com/internacional/2019/06/20/america/1561059910_686553.html

TelesurTv, 2019, 6 de noviembre. "Indígenas hondureños revelan exterminio contra pueblo garífuna." Recuperado el 12 de abril de 2020 de: https: / / www.telesurtv.net/news/honduras-garifunas-plan-exterminio-narcotrafico-crimen-organizado-20191106-0018. html

Tourliere, Mathieu. 2020, 29 de enero. “Con 'Quédate en México' EU devolvió a México más de 62 mil solicitantes de asilo." Proceso. Recuperado el 17 de abril de 2020 de: https: / / www.proceso.com.mx/616034/eu-devolvio-62-mil-solicitantes-de-asilo-en-2019

Transparencia Internacional, 2020. Índice de Percepción de Corrupción. Recuperado el 26 de marzo de 2020 de: www.transparency.org

Unidad de Política Migratoria. 2020. Secretaría de Gobernación. Recuperado el 14 de marzo de: http://portales.segob.gob.mx/es/PoliticaMigratoria/Direccion_de_Estadistica 
U.S. Boarder Patrol Nationwide Aprehensions by Citizenship and Sector. 2019. U.S. Department of Homeland Securuty. Recuperado el 14 de marzo de: https:/ /www.cbp.gov / sites/default/files/assets/documents/2018-Jul/usbp-nationwide-apps-sector-citizenship-fy07-fy17.pdf

Weiss, Sandra. 2019, 24 de junio. "Honduras: un país en crisis y un presidente en apuros." DW. Recuperado el 26 de junio de 2019 de: https:/ /www.dw.com/es/honduras-unpa\%C3\%ADs-en-crisis-y-un-presidente-en-apuros/a-49335201

Recibido: 29 de abril de 2020

Aceptado: 26 de junio de 2020

Cecilia Graciela Rodríguez. Doctora en Ciencia Política por la Universidad de Salamanca. Profesora asociada en el Área de Ciencia Política y de la Administración de la Universidad de Salamanca e Investigadora del Instituto de Iberoamérica de la Universidad de Salamanca. Entre sus líneas de investigación destacan las instituciones políticas, las élites políticas, los procesos electorales y la participación política de la mujer, siendo autora de varios artículos vinculados a estos temas con especial énfasis en América Latina. Email: ceci_rodriguez@usal.es

Luis González Tule. Doctor en Ciencia Política de la Universidad de Salamanca. Profesor asistente en el Departamento de Ciencia Política y Relaciones Internacionales de la Universidad del Norte (Uninorte) y miembro del Sistema Nacional de Investigadores (SNI, nivel 1) del Consejo Nacional de Ciencia y Tecnología de México (CONACYT). Ha publicado artículos sobre partidos políticos y procesos electorales en las revistas América Latina Hoy, Mexicana de Sociología y Política y Gobierno. Email: 1tule@uninorte.edu.co 